\section{Narrative health psychology: Once more unto the breach}

\author{
Anneke M Sools ${ }^{1}$, Michael Murray ${ }^{2}$ and \\ Gerben J Westerhof ${ }^{1}$
}

Journal of Health Psychology

$1-7$

(C) The Author(s) 2015

Reprints and permissions: sagepub.co.uk/journalsPermissions.nav DOI: $10.1177 / 1359105314566616$ hpq.sagepub.com

\begin{abstract}
In this editorial, we position narrative health psychology as a variety of narrative psychology, a form of qualitative research in health psychology, and a psychological perspective that falls under the interdisciplinary term narrative health research. The aim of this positioning is to explore what are the most important features of the proposed approach and how they are relevant. We illustrate each positioning with the scope and diversity of narrative health psychology brought together in this special issue. Finally, we reflect on where narrative health psychology is now and how it could develop in the future.
\end{abstract}

\title{
Keywords
}

clinical health psychology, community health psychology, critical health psychology, narratives, qualitative methods, well-being

Breaches of the canonical, like the scripts breached, are often highly conventional and are strongly influenced by narrative traditions. Such breaches are readily recognizable as familiar human plights - the betrayed wife, the cuckolded husband, the fleeced innocent, and so on [...] But both scripts and their breaches also provide rich grounds for innovation-as witness the contemporary literary journalistic invention of the "yuppy" script or the formulation of the white criminal's breach. And this is, perhaps, what makes the innovative storyteller such a powerful figure in a culture. He may go beyond the conventional scripts, leading people to see human happenings in a fresh way, indeed in a way they had never "noticed" or even dreamed.

Bruner (1991)

Narrative health psychology is a rather small and emerging field that has the potential of "breaching" mainstream health psychology again and again, thereby making visible both conyentionality and novelty in research approaches, methods, and topics. That narrative health psychology is an emerging field becomes apparent when we take a look at some figures. A quick scan of the Web of Science reveals that from over 10,000 articles about health and psychology (key words of the topic) which were published between 2005 and 2014, a total of 219 refer to "narrative." The prevalence of articles about narrative psychology more generally is higher with almost 1500 published articles in the same time span, but still relatively small considering

1University of Twente, The Netherlands

${ }^{2}$ Keele University, UK

\section{Corresponding author:}

Anneke M Sools, Department of Psychology, Health \& Technology, University of Twente, P.0. Box 217, 7500 AE Enschede, The Netherlands.

Email: a.m.sools@utwente.nl 
that narrative as key word occurs almost 70,000 times in articles across disciplines. To make clear what this small field has to offer, we position it in three ways in this editorial: a variety of narrative psychology, a form of qualitative research in health psychology, and a perspective within an interdisciplinary field of narrative health research. We illustrate each positioning with the scope and diversity of narrative health psychology brought together in this special issue. Finally, we reflect on where narrative health psychology is now and how it could develop in the future.

\section{Narrative health psychology as a form of narrative psychology}

A first way of positioning narrative health psychology is taking it as a specific form of narrative psychology. Although stories and storytelling have been an intrinsic part of psychology since the emergence of the discipline, a narrative approach became more prominently and explicitly articulated in the 1980s. This early period of narrative psychology is marked by the publication of seminal works by Jerome Bruner (1986, 1990), Ted Sarbin (1986), Donald Polkinghorne (1988), and Eliot Mishler (1986). It was followed in the 1990s with works by Mark Freeman (1993), Amia Lieblich and Ruthellen Josselson (1993), Dan McAdams (1993), and Jens Brockmeier and Donal Carbaugh (2001).[AQ1] Although this list is far from comprehensive, together these works give a flavor of the goal of narrative psychology to produce contextual accounts of the meaning and experience of everyday lives and identity. Nowadays, the narrative approach has come to be an established perspective in personality psychology, focusing in particular on the development of self and identity (Crossley, 2000; McAdams, 2008; McAdams and McLean, 2013) and mental health (Westerhof and Bohlmeijer, 2012, 2014). Narratives are intimately involved in the construction of lives and identities that are not dominated by life problems, and thereby contribute to mental health and well-being.

Narrative health psychology can be similarly positioned as studying the lived experience of health and illness through storied accounts of lay people, patients, and professionals. The articles in this issue address a wide range of significant health topics in specific groups: the representation of respiratory disorders by artists (Kaptein et al., 2015), cancer in children (Moore et al., 2015), extreme pain in rehabilitation therapy (Mundle, 2015), post-traumatic stress in combat veterans (Caddick et al., 2015), problem gambling in Chinese international students (Li and Tse, 2015), eating disorders in athletes (Papathomas et al., 2015), outreach professionals in alcohol and drugs prevention (Van Vuuren and Westerhof, 2015), community workers challenging health inequalities (Murray, 2015), and future imagination (Sools et al., 2015). All articles share a common approach in that they take the voice of patients and health professionals seriously. They thus remain close to the goal of narrative health psychology to study the lived experiences of health and illness.

Interestingly, most contributions focus on how stories provide insight in the broader meanings of the health problems encountered. The main insight that comes to the fore when reading these articles is that when we take the voice of patients and professionals seriously, there is more to health problems than being ill: strengths, social connections, well-being, spirituality, future imagination. In this way, the voice of patients and professionals becomes contextualized within life. The last commonality of the studies is that they envision how current healthcare practices could be improved by taking the voice of patients and professionals seriously. Some articles pave the way for improving healthcare along these lines whereas others give very 
specific advice on how to approach this (Kaptein et al., 2015; Moore et al., 2015; Mundle, 2015). These studies show how narrative approaches are suited to bridging the gap between research and practice in health psychology.

\section{Narrative health psychology as a branch of qualitative health psychology}

A second way of positioning narrative health psychology is to see it as a particular branch of qualitative health psychology. Since an early call for inclusion of qualitative methods in the field (Chamberlain et al., 1996), there has been a slow but steady rise in published research using qualitative methods in health psychology.[AQ2] In our view, the insights provided by qualitative methods (including narrative) in health psychology are not opposed but complementary to knowledge gained with quantitative methods. Qualitative methods (including narrative ones) are "focused more holistically, value experience, and seek understanding which incorporates social context" (Chamberlain et al., 1996). While a choice of good text books exists about how to do other qualitative research (e.g. discourse analysis, grounded theory, and interpretive phenomenological analysis), texts on how to do narrative research have only recently emerged. The few methodological texts (Andrews et al., 2008; De Fina and Georgakopoulou, 2012; Riessman, 2008) and chapters (Murray, 2003; Murray and Sools, 2014; Sools and Murray, 2014) available tend to offer a variety of narrative approaches and showcase different versions of narrative research.

Given these remarks about the variety of methods, it is interesting to see the variety of approaches used in the studies reported in this issue. The studies vary substantially in how narratives of different stakeholders were collected and analyzed. Although the most frequently used method of data collection remains the interview, narrative researchers are keen to explore other sources of narrative data and different ways of treating interview material. $\mathrm{Li}$ and Tse (2015) reconstructed the interviews to form chronological accounts. Kaptein et al. consider the value of artistic sources of narratives in novels, poems, movies, music, and paintings. Sools et al. consider the potential value of written narratives (letters from the future). Caddick et al. supplemented their interviews with participant observation. Moore et al. draw on a literature review. We consider broadening the scope of narrative methods as a way to opening up avenues for more sophisticated understanding through the triangulation of different narrative approaches.

Having said this, the methods used differ on at least two important dimensions. The first dimension concerns how voices are a unique expression of a particular individual versus a more collective expression of people in a similar context. At the one end of this dimension, case studies (Mundle, 2015) provide an in-depth analysis of a single voice. At the other end of the dimension, there are collective voices that are used to make sense of peer relations within a group (Caddick et al., 2015). In between, there are studies that draw in different ways on multiple voices. Murray and Ziegler draw from a broader study that provides the background to different individual voices that are highlighted as they are especially expressive for the experiences of community workers. Papathomas et al. bring different voices within one family (daughter, mother, and father) to life and show commonalities and differences in these voices. $\mathrm{Li}$ and Tse (2015) grouped individual voices under common themes. Sools et al. studied how individual voices of articulating the future self are patterned. Van Vuuren and Westerhof treat the voices of different individuals as expressions of a broader collective voice.

The second dimension refers to the way that stories are contextualized and brings the multilayered characteristics of narratives 
clearly to the fore. Some studies focus on the functionality, meaning, and structure of stories (Kaptein et al., 2015; Sools et al., 2015), others focus on how identities are situated in place ( $\mathrm{Li}$ and Tse, 2015; Van Vuuren and Westerhof, 2015), how stories are dialogically co-constructed (Caddick et al., 2015; Moore et al., 2015; Mundle, 2015; Papathomas et al., 2015), or how they related to broader societal dynamics (Murray, 2015). It should be noted that these two dimensions are not independent from each other and that they have important implications for both the data collection and analysis.

\section{Narrative health psychology as a perspective in narrative health research}

The third way of positioning narrative health psychology is as a specific perspective within the broader interdisciplinary field of narrative health research. The use of a narrative approach in various health-related disciplines demonstrates "that narrative has become an established approach in health research" (Sools, 2013).[AQ3] Narrative approaches have, for example, been integrated and applied to various medical and health-related disciplines such as medical sociology (Frank, 1995; Riessman, 2008), narrative medicine (Charon, 2008; Greenhalgh and Hurwitz, 1998), narrative therapy (White and Epston, 1990), medical anthropology (Kleinman, 1988; Mattingly and Garro, 2000), and narrative gerontology (Kenyon et al., 2011).[AQ4] Many arguments in favor of an interdisciplinary narrative approach in health research more generally also apply to narrative health psychology. These arguments include the possibility to address what is morally, ideologically, and emotionally "at stake" when people talk about health and illness (Kleinman and Seeman, 2000; Radley and Billig, 1996), to address multiple levels of analysis (Murray,
2000), and to make use of the narrative structure of health accounts (Murray, 2002).

It should be noted, however, that a too neat division between disciplines using a narrative approach is to some extent misleading, and that part of the attraction of narrative research is its multidisciplinary character. A particularly noteworthy recent example is the book HIV in South Africa: Talking about the Big Thing by psychologist Corinne Squire (2007) which received the Sociology of Health and Illness/British Sociological Association book prize in 2008.[AQ5] The interdisciplinary nature of narrative research is also reflected in the range of journals devoted to narrative research (e.g. Narrative Inquiry) and the conferences/societies on the topic (e.g. Narrative Matters). The possibility to transcend disciplinary borders is a key feature of narrative health research.

This interdisciplinarity can also be found in the present issue. The authors have made use of different theoretical approaches, including the literary work on polyvocality by Bakhtin (Caddick et al., 2015), the medical sociological work on illness stories by Frank (Caddick et al., 2015; Papathomas et al., 2015), the work in narrative therapy on definitional ceremonies by White and Epstein (Moore et al., 2015), the cognitive psychology of space by Tversky (Van Vuuren and Westerhof, 2015), work from environmental psychology and cultural psychology on spatial identity ( $\mathrm{Li}$ and Tse, 2015), the field of narrative medicine and medical humanities (Kaptein et al., 2015), the ideas of community development (Murray, 2015), and interpretive epistemology from hermeneutics (Sools et al., 2015). The articles show that this interdisciplinarity is not opposed to strengthening a narrative approach within one specific discipline, for example, health psychology. Rather, they show that different narrative approaches contribute to a more situated, contextualized, interactional approach as proposed by health psychologists who are critical of a too individualistic 
psychology that does not take into account the broader social context and the myriad structural inequalities.

\section{Concluding remarks}

In this editorial, we have highlighted the contributions that narrative health psychology has to offer to the field of health psychology, as a disciplinary psychological approach of narrative, as a variety of ways of doing qualitative research and as an interdisciplinary approach. Across the three different types of positioning, we see that the goal of narrative health psychology is to provide people with a voice in telling their stories about the lived experience of health and illness. We have seen that the field has a number of different ways of doing research and has important interdisciplinary characteristics. This special issue thus illustrates the promise of narrative health psychology in its variety of topics and methods.

The variety

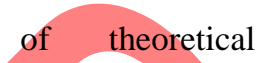
methodological approaches in this special issue also shows that narrative health psychology is still an emerging field. To be sure, this issue does not provide a true state of the art as important approaches are still missing. For example, the more nomothetic approaches like the work of Pennebaker on expressive writing (Pennebaker and Chung, 2011), or the work of McAdams (2006) on redemptive stories.[AQ6] Some critical approaches are also not represented, like those from feminist or psychoanalytical theory (e.g. the work of Haaken (2010) on domestic violence) or those that concern the relationship between what variously has been called dominant, master, or canonical narratives on the one hand and personal, alternative, or counter narrative on the other hand (Hammack, 2008; McKenzie-Mohr and Lafrance, 2014).

This diversity can be seen as a strength of narrative research as further standardization might detract from the necessary creativity and flexibility which is an intrinsic part of this approach. It might also be considered a weakness, as beginning researchers often experience difficulty to find their way in this diverse and fragmented field (Sools, 2013) and it might hinder the dissemination and accumulation of knowledge in the field. We hope that this issue will be seen as an important step to bring the variety to the fore. Making the variety explicit will be helpful for further narrative researchers to make choices about their theories and methods and to position themselves in the field. Moreover, this special issue once more brings to the fore how narrative can offer a bridge between research and action that starts from human experience and the quest for a meaningful life. This starting point is much needed in times of scarcity in healthcare and timely in light of growing recognition that research programmes should have practical and societal relevance.

\section{Acknowledgements[AQ7]}

We would like to acknowledge the very generous commentaries provided by the many reviewers for this special issue. Their names will be included in a final listing of reviewers. We received many submissions and it was a difficult decision on the final selection. Those articles that included one of the editors as a co-author were dealt with anonymously by one of the other co-editors and were subject to the same review process.

\section{Funding}

This research received no specific grant from any funding agency in the public, commercial, or notfor-profit sectors.

\section{References}

Andrews M, Squire C and Tamboukou M (2008) Doing Narrative Research. London: SAGE.

Brockmeier J and Carbaugh D (2001) Narrative and Identity. Studies in Autobiography, Self and 
Culture. Amsterdam; Philadelphia, PA: John Benjamins.

Bruner J (1986) Actual Minds, Possible Worlds. Cambridge, MA: Harvard University Press.

Bruner J (1990) Acts of Meaning. Cambridge, MA: Harvard University Press.

Bruner J (1991) The narrative construction of reality. Critical Inquiry 18: 1-20.[A08]

Caddick N, Phoenix C and Smith B (2015) Collective stories and well-being: Using a dialogical narrative approach to understand peer relationships among combat veterans experiencing PTSD. Journal of Health Psychology, IN PRESS.

Charon R (2008) Narrative Medicine: Honoring the Stories of Illness. New York: Oxford University Press.

Crossley M (2000) Introducing Narrative Psychology: Self, Trauma and the Construction of Meaning. Buckingham: Open University Press.

De Fina A and Georgakopoulou A (2012) Analysing Narrative. Discourse and Sociolinguistic Perspectives. Cambridge: Cambridge University Press.

Freeman M (1993) Rewriting the Self. History, Memory, Narrative. London: Routledge.

Greenhalg T and Hurwitz B (1998) NarrativeBased Medicine. London: BMJ Books.

Haaken J (2010) Hard Knocks. Domestic Violence and the Psychology of Storytelling. London: Routledge.

Hammack PL (2008) Narrative and the cultural psychology of identity. Personality and Social Psychology Review 12: 222-247.

Kaptein AA, Meulenberg F and Smyth JM (2015) A breath of fresh air: Images of respiratory illness in novels, poems, films, music, and paintings. Journal of Health Psychology, IN PRESS.

Kenyon G, Bohlmeijer E and Randall WL (2011) Storying Later Life. New York: Oxford University Press.

Kleinman A (1988) The Illness Narratives: Suffering, Healing, and the Human Condition. New York: Basic Books.

Kleinman A and Seeman D (2000) Personal experience of illness. In: Albrecht G, Fitzpatrick $\mathrm{R}$ and Scrimshaw S (eds) Handbook of Social Studies in Health and Medicine. London: SAGE, pp. 230-242.[AQ9]
Laszlo J (2008) The Science of Stories. London: Routledge.[AQ10]

Lieblich A and Josselson R (1993) The Narrative Study of Lives. London: SAGE.

Li W and Tse S (2015) Problem gambling and help seeking among Chinese international students: Narratives of place identity transformation. Journal of Health Psychology, IN PRESS.

McAdams D (1997) The Stories We Live by: Personal Myths and the Making of the Self. New York: Morrow.[AQ11]

McAdams D (2008) Personal narratives and the life story. In: Jøhn OP, Robins RW and Pervin LA (eds) Handbook of Personality Psychology: Theory and Research (3rd edn). New York: Guilford Press, pp. 242-262.

McAdams D and McLean KC (2013) Narrative identity. Current Directions in Psychological Science 22: 233-238.

McKenzie-Mohr S and Lafrance MN (2014) Women Voicing Resistance. Discursive and Narrative Explorations. London: Routledge.

Mattingly C (1998) Healing Dramas and Clinical Plots. The Narrative Structure of Experience. New York: Cambridge University Press.[A012]

Mattingly C and Garro LC (2000) Narrative and the Cultural Construction of Illness. Berkeley, CA: University of California Press.

Mishler E (1986) Research Interviewing, Context and Narrative. Cambridge, MA: Harvard University Press.

Moore K, Moxley-Haegert L and Talwar V (2015) Definitional ceremonies: Narrative practices for psychologists to inform interdisciplinary teams' understanding of children's spirituality in pediatric settings. Journal of Health Psychology, IN PRESS.

Mundle R (2015) A narrative analysis of spiritual distress in geriatric physical rehabilitation. Journal of Health Psychology, IN PRESS.

Murray M (1997) A narrative approach to health psychology: Background and potential. Journal of Health Psychology 2: 9-21.[A013]

Murray M (1999) The storied nature of health and illness. In: Murray M and Chamberlain K (eds) Qualitative Health Psychology: Theories and Methods. London: SAGE, pp. 47-63.[AQ14]

Murray M (2000) Levels of narrative analysis in health psychology. Journal of Health Psychology 5(3): 331-342. 
Murray M (2002) Connecting narrative and social representation theory in health research. Social Science Information 41(4): 653-673.

Murray M (2003) Narrative psychology. In: Smith J (ed.) Qualitative Psychology: A Practical Guide to Research Methods. London: SAGE, pp. 111-131.

Murray M (2015) The narrative psychology of community work. Journal of Health Psychology, IN PRESS.

Murray M and Sools A (2014) Narrative research. In: Rohleder P and Lyons A (eds) Qualitative Research in Clinical and Health Psychology. London: Palgrave, pp. 133-154.

Papathomas A, Smith B and Lavallee D (2015) Family experiences of living with an eating disorder: A narrative analysis. Journal of Health Psychology, IN PRESS.

Pennebaker JW and Chung CK (2011) Expressive writing and its links to mental and physical health. In: Friedman HS (ed.) Oxford Handbook of Health Psychology. New York: Oxford University Press, pp. 417-437.

Polkinghorne D (1988) Narrative Knowing and the Human Sciences. Albany, NY: SUNY Press.[A015]

Radley A and Billig M (1996) Accounts of health and illness: Dilemmas and representations. Sociology of Health \& Illness 18: 220-240.

Ricoeur P (1984) Time and Narrative, vol. 1. Chicago, IL: University of Chicago Press.[AQ16]

Riessman CK (2008) Narrative Methods for the Human Sciences. London: SAGE.
Sarbin T (1986) Narrative Psychology: The Storied Nature of Human Conduct. New York: Praeger.

Sools A (2013) Narrative health research: Exploring big and small stories as analytical tools. Health 17: 93-110.

Sools A and Murray M (2014) Promoting health through narrative practice. In: Murray M (ed.) Critical Health Psychology (2nd edn). London: Palgrave, pp. 235-253.

Sools A, Tromp T and Mooren JH (2015) Mapping letters from the future: Exploring narrative processes of imagining the future. Journal of Health Psychology, IN PRESS.

Van Vuuren M and Westerhof GJ (2015) Identity as 'knowing your place': The narrative construction of space in a healthcare profession. Journal of Health Psychology, IN PRESS.

Westerhof GJ and Bohlmeijer E (2012) Life stories and mental health: The role of identification processes in theory and interventions. Narrative Works 2(1): 106-128.

Westerhof GJ and Bohlmeijer ET (2014) Celebrating fifty years of research and applications in reminiscence and life review: State of the art and new directions. Journal of Aging Studies 29: 107-114.

White M and Epston D (1990) Narrative Means to Therapeutic Ends. New York: W. W. Norton.[AQ17] 